\title{
Grammatiese inligting ten opsigte van adjektiewe in aanleerderwoordeboeke*
}

\author{
Anna Nel Otto, Departement Afrikaans, Universiteit Vista, \\ Port Elizabeth, Suid-Afrika
}

\begin{abstract}
Grammatical Information with Regard to Adjectives in Leamer's Dictionaries. Because a learner's dictionary is used for both decoding and encoding it should contain far more grammatical information (explicitly indicated) than standard dictionaries. Therefore, with regard to adjectives for example, attention should be given to the following: the possibility or not of inflection; the comparative and superlative forms; a complete identification of the different types of adjectives, an indication whether an adjective can only be used attributively or predicatively; the different ways in which so and sulke are used; the fact that not all "past participles" can be derived from the passive forms of wees; the provision of a spelling list with the names of people, countries, places, nations, tribes, languages, as well as derivations thereof; cross-references between nouns/verbs and their adjectival correlates if there are striking differences between them, and an indication of adjective complements. The value of valency theory by determining adjective complements is examined in this article and the importance of a distinction between obligatory and peripheral complements for both learners and teachers is stressed. The linguistic categories which can function as adjective complements in Afrikaans are provisionally indicated, but it is stated that further research in this regard is necessary.
\end{abstract}

Keywords: ADJECTIVE, ADJECTIVE COMPLEMENTS, GRAMMATICAL INFORMATION, LEARNER'S DICTIONARY, LINGUISTIC CATEGORIES, MICRO-STRUCTURE, MINI GRAMMAR, OBLIGATORY COMPLEMENTS, OPTIONAL COMPLEMENTS, PERIPHERAL COMPLEMENTS, VALENCY

Opsomming: Aangesien in aanleerderwoordeboek vir sowel dekodering as enkodering gebruik word, moet dit baie meer grammatiese inligting (eksplisiet aangedui) as standaardwoordeboeke bevat. Gevolglik moet daar byvoorbeeld ten opsigte van adjektiewe aandag geskenk word aan: 'n aanduiding of adjektiewe verbuig moet word of nie, trappe van vergelyking, ' $n$ volledige identifikasie van adjektiewe, ' $n$ aanduiding of adjektiewe net attributief of net predikatief kan optree, die verskillende wyses waarop so en sulke gebruik word, die feit dat nie alle "voltooide deelwoorde" uit lydende vorme met wees gevorm kan word nie, die voorsiening van 'n spellys met die name van mense, lande, plekke, volkere, stamme, tale, asook afleidings daarvan, kruisverwysings tussen selfstandige naamwoorde/werkwoorde en hul adjektiwiese korrelate indien daar

Hierdie artikel is 'n verkorte en aangepaste hoofstuk uit 'n D.Litt-verhandeling, Kriteria vir 'n Afrikaanse aanleerderwoordeboek, wat in 1989 deur die Universiteit van Stellenbosch aanvaar is. 
groot verskille tussen hulle is, en die aandui van adjektiefkomplemente. Die waarde van valensieteorie by die bepaling van adjektiefkomplemente word ondersoek en daar word gewys op die belangrikheid van 'n onderskeid tussen verpligte en perifere komplemente vir sowel aanleerders as onderwysers. Die linguistiese kategorieë wat in Afrikaans as adjektiefkomplemente kan optree, word voorlopig aangedui, maar daar word op gewys dat verdere navorsing oor hierdie aspek nodig is.

Sleutelwoorde: AANLEERDEEROORDEBOEK, ADJEKTIEFKOMPLEMENTE, ADJEKTIEWE, GRAMMATIESE INLIGTING, LINGUISTIESE KATEGORIEë, MIKROSTRUKTUUR, MINICRAMMATIKA, OPSIONELE KOMPLEMENTE, PERIFERE ELEMENTE, VALENSIE, VERPLIGTE KOMPLEMENTE

\section{Inleidend}

Grammatiese inligting in woordeboeke sluit sowel sintaktiese as morfologiese inligting in. Dié inligting kan enersyds in die mikrostruktuur 'n neerslag vind as eksplisiete gegewens oor bepaalde lemmas. Andersyds kan dit in die minigrammatika los van die woordeboek se alfabetiese deel aangebied word (Gouws 1986: 27).

Die inkorporering van.grammatiese inligting in 'n aanleerderwoordeboek behoort so volledig as moontlik aangebied te word ten einde die aanleerder in staat te stel om op grond van die leiding wat hy ontvang, selfstandig korrekte, natuurlike sinne te genereer.

Aangesien grammatiese inligting voorkom as inskrywings in ' $n$ woordeboekartikel maak dit deel uit van 'n woordeboek se mikrostruktuur. Hierdie soort inligting val in twee hoofkategorieë uiteen, naamlik eksplisiete inligting en implisiete inligting. Die mate waarin aandag geskenk word aan hierdie twee tipes inligting word bepaal deur die betrokke woordeboeksoort.

Eksplisiete inligting word in die meeste woordeboeke voor die definiens geplaas. Volgens Jackson (1985: 54) is daar vier tipes inligting wat van woordeboekartikels verlang kan word. Die eerste drie tipes verteenwoordig eksplisiete inligting. Eerstens is daar inligting oor die wyse waarop 'n leksikale item verbuig kan word, veral wanneer dit nie afleibaar is uit die algemene reëls van die grammatika nie. Tweedens is daar woordsoortaanduiding. Derdens kan meer spesifieke eksplisiete sintaktiese inligting gegee word, byvoorbeeld werkwoorde wat geklassifiseer word as oorganklik of onoorganklik. Volgens Jackson (1985: 54) is lg. tipe inligting van besonder groot belang vir die tweedetaalgebruiker.

Die vierde tipe hou verband met implisiete grammatiese inligting wat onregstreeks met behulp van goed gekose voorbeeldsinne en kollokasies aangebied word. Dit word gewoonlik ná die definiens geplaas.

Die woordeboekgebruiker moet nie slegs in staat gestel word om effektief te kan kommunikeer nie, maar die leksikograaf moet self ook effektief kommu- 
nikeer met die woordeboekgebruiker sodat woordeboekartikels sinvol ontsluit kan word.

Die inligting wat in die toeligtende aantekeninge van 'n woordeboek weergegee word, is tweeledig van aard. 'n Deel van dié inligting het die sinvolle ontsluiting van die woordeboekartikels ten doel. Die ander deel van die inligting kom voor as 'n minigrammatika, dit wil sê 'n betroubare samevatting van die taal se grammatika (Gouws 1986: 29).

Die minigrammatika kan op verskillende wyses aangebièd word. Dit kan byvoorbeeld op so 'n wyse by die grammatiese mikrostruktuurinligting geïntegreer word dat die woordeboekartikels 'n reeks kodes bevat wat in die minigrammatika geëkspliseer word. Gouws (1986: 30) noem die volgende tipes inligting wat vir Afrikaans deur bogenoemde wyse van kodering en kruisverwysing gegee kan word: woordsoortaanduiding en talle onderafdelings wat daarmee verband hou, byvoorbeeld die attributiewe of predikatiewe gebruik van adjektiewe, adjektiwiese verbuigings, trappe van vergelyking, substantiwiese gebruik van adjektiewe, oorganklikheid en onoorganklikheid van werkwoorde, moontlikheid om werkwoorde in die lydende vorm te gebruik, te of -de as uitgange by voltooide deelwoorde, deelwoordvorming as sodanig, optrede van 'n voegsel waar die lemma in kompositumverband optree, ensovoorts.

Die minigrammatika kan ook die vorm aanneem van 'n beknopte beskrywing van bepaalde grammatiese aspekte van die taal. So 'n minigrammatika moet veral konsentreer op morfologiese en sintaktiese reëlmatighede (Gouws 1986: 30).

Volgens Gouws (1986: 30) is die ideaal dat woordeboekgebruikers met behulp van die woordeboekartikel by dié minigrammatika moet kan uitkom. Die gebruik van direkte kruisverwysing kan verseker dat die twee grammatiese inligtingskategorieë in 'n interaktiewe verhouding benut word. In dié verband kan woordeboekgebruikers baie baat vind by onderrig in woordeboekontsluitingsvaardighede.

\section{Kriteria ten opsigte van die aanduiding van adjektiewe}

Afrikaanse woordeboeke en Bosman e.a. se Tweetalige Woordeboek/Bilingual Dictionary dui adjektiewe as sodanig aan, maar genoegsame inligting word nie aan aanleerders verskaf om hulle in staat te stel om adjektiewe korrek (d.w.s. vir enkodering) te gebruik nie. Om voorsiening te maak vir die aanleerder se behoefte aan meer gedetailleerde inligting, moet adjektiewe op 'n andersoortige wyse in aanleerderwoordeboeke behandel word.

Die inligting wat noodsaaklik is om adjektiewe korrek te kan gebruik, word vervolgens bespreek. 


\subsection{Algemene kriteria}

'n Aanduiding of die adjektief die attributiewe verbuigingselement - $e$ moet neem of nie is noodsaaklik en dit behoort eksplisiet aangedui te word. Indien dit moontlik is dat 'n bepaalde adjektief met of sonder die - e gebruik kan word, behoort ook dít eksplisiet aangedui te word. In lg. gevalle verbind die adjektiewe met $-e$ dikwels met 'n vaste naamwoord(e) en verkry ' $n$ figuurlike of idiomatiese betekenis wat uit die voorbeeldsinne moet blyk. In sodanige gevalle behoort nagegaan te word of hulle as lemmas opgeneem moet word of nie. Vergelyk diepe waters.

- Die trappe van vergelyking van die betrokke adjektief behoort aangedui te word. Daar behoort op 'n duidelike wyse onderskei te word tussen adjektiewe waarvan die vergelyking deur -er en -ste (d.w.s. morfologies) gevorm word en adjektiewe wat meer en mees neem (d.w.s. leksikale gradering - vergelyk Carstens 1991: 78, 79). Indien die trappe van vergelyking op beide morfologiese en leksikale wyses gevorm kan word, behoort dit ook so aangedui te word. Hierdie kriterium verteenwoordig 'n ideaal wat nagestreef behoort te word. Op die oomblik is die vergrotende en oortreffende trappe van adjektiewe in Afrikaans onvas as gevolg van Engelse invloed.

Onreëlmatige vorme behoort ook aandag te geniet. In Afrikaans sal daar dan in hierdie verband aandag geskenk moet word aan die adjektiewe baie, goed, graag, naby en weinig wat suppletiewe (morfologies onverwante) graadtrappe het:

$\begin{array}{lll}\text { (1) baie } & \text { meer } & \text { meeste } \\ \text { goed } & \text { beter } & \text { beste } \\ \text { graag } & \text { liewer } & \text { graagste/liefste } \\ \text { naby } & \text { nader } & \text { naaste } \\ \text { weinig } & \text { minder } & \text { minste }\end{array}$

(Vergelyk Ponelis 1979: 279).

Asimmetriese trappe soos die onderstaande verdien ook aandag:

(2) afgeleë bek-af ideaal pootuit

$\begin{array}{ll}\text { meer afgeleë } & \text { afgeleënste } \\ \text { meer bek-af } & \text { bek-afste } \\ \text { meer ideaal } & \text { ideaalste } \\ \text { meer pootuit } & \text { pootuitste }\end{array}$

(Vergelyk Ponelis 1979: 279). 
Beide die Nasionale Woordeboek (voortaan NW) en Handwoordeboek van die Afrikaanse Taal (voortaan HAT) dui nie die asimmetriese trappe van bogenoemde woorde aan nie. Die feit dat die betrokke woordeboeke nie die trappe van vergelyking van hierdie adjektiewe aandui nie, impliseer dat hulle nie so gebruik kan word nie.

- Adjektiewe (wat wel gradeerbaar is), moet onderskei word van die adjektiewe wat nie gradeerbaar is nie, soos byvoorbeeld aaneenskakelend. 'n ldentifikasie van adjektiewe is noodsaaklik, met ander woorde 'n aanduiding of die adjektief selfstandig, oorganklik, 'n voorsetseladjektief of ' $n$ adjektief gevolg deur ' $n$ infinitiefsin is. Voorbeelde hiervan is:

(3) (a) Selfstandige adjektief,

- Die seun is ongelukkig.

(b) Oorganklike adjektief

- Hy is Xhosa magtig.

(c) Voorsetseladjektief

- Sy is vertroud met die reëls.

(d) Adjektief en infinitiefsin

- Ek is nie lus om nou te gaan swem nie.

Hierdie inligting kan deur middel van kodes aangedui word. In die toeligtingsgedeelte kan hierdie kodes en die verskillende soorte adjektiewe dan verduidelik word.

Sommige adjektiewe kan sowel attributief as predikatief optree. Sulke adjektiewe hoef nie vir dié optredes gemerk te word nie, maar daar is ook ander adjektiewe wat beperk is in hul optrede deurdat hulle of net attributief óf net predikatief gebruik kan word. Dit is 'n gemerkte waarde wat aangetoon moet word (Gouws 1989: 225). Adjektiewe wat net attributief of net predikatief optree, kan deur middel van kodes as sodanig geïdentifiseer word.

Adjektiewe wat net predikatief kan optree, is onder meer begaan, bestund, gedagtig, gewoond, kwaad, vatbaar, gesteld. (De Villiers 1983: 58).

"Onder die adjektiewe wat net attributief voorkom, is ' $n$ baie belangrike groep naamwoordelik van aard, byvoorbeeld provinsiale, regterlike, ministeriële, botaniese, mediese, chemiese, stedelike, ens." (De Villiers 1983: 58).

Aanleerders moet gewys word op die onderskeid tussen so en sulke. Die aanwysende PRO-adjektief so verskyn net in onbepaalde naamwoordstukke, byvoorbeeld so 'n seun. Voor enkelvoudige soortnaamwoorde het dit die vorm so, maar voor massanaamwoorde en meervoudige soortraamwoorde tree sulke op: sulke seuns, sulke onsin (vergelyk Ponelis 1979: 152). Sommige aanleerders gebruik sulke voor enkelvoudige soortnaamwoorde. Dit is dus belangrik dat aan hulle eksplisiet voorgehou word hoe om so en sulke korrek te gebruik. Dié inligting kan deur 
middel van 'n gebruiksnota oorgedra word en voorbeelde kan ter illustrasie gebruik word.

- Nie alle "voltooide deelwoorde" kan uit lydende vorme met wees gevorm word nie. Vergelyk:

(4) gesingde versie

gegooide klip

gesiende plek

Hierdie beperkings behoort onder die aandag van die gebruiker gebring te word. Indien daar byvoorbeeld in die woordeboek deurgaans (teenwoordige en voltooide) deelwoorde by die lemma aangedui word, sal die weglating impliseer dat die deelwoorde nie moontlik is nie. ' $n$ Alternatief is om ' $n$ volledige lys stamme en deelwoorde voor of agter in die woordeboek aan te bring. Woorde wat nie in hierdie lys voorkom nie, kan dan nie as deelwoorde gebruik word nie.

- Dit is verder ook noodsaaklik dat 'n spellys met die name van mense, lande, plekke, volkere, stamme, tale, asook afleidings daarvan, voorsien behoort te word, aangesien die spelling van die basisvorm en afleiding dikwels baie verskil. Vergelyk:
(5) Genève
-
Geneefse
Algerië
Algerynse
Kreta
Kretensiese

- By Germaanse teenoor Romaanse sinonimie is daar dikwels 'n groot verskil tussen naamwoordstamme en hul adjektiwiese korrelate, gevolglik behoort daar kruisverwysings van die naamwoord na die adjektief en omgekeerd te wees. ' $n$ Altematief is om gebruiksnotas te gebruik. Vergelyk:

\section{Samestelling}

(6) eindstaat

buite-oor

oogsenuwee

taalverskynsels

\author{
Adjektief + naamwoord \\ finale staat \\ eksterne oor \\ optiese senuwee \\ linguistiese verskynsels
}

(Vergelyk Ponelis 1979: 147).

- Daar behoort ook kruisverwysings tussen werkwoorde en hul adjektiwiese korrelate te wees indien daar groot verskille is. Vergelyk: 


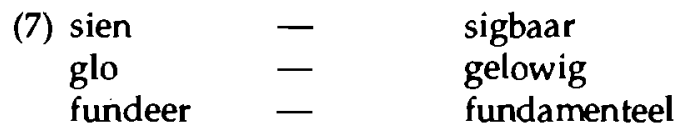

\subsection{Kriteria met betrekking tot adjektiefkomplemente}

Adjektiefkomplemente behoort aangedui te word.

Reeds in 1899 het Henry Sweet in sy,Practical Study of Languages die volgende vereiste aan woordeboeke vir nie-moedertaalsprekers gestel:

"A thoroughly useful dictionary ... ought to give full information about those grammatical constructions which characterize individual words and cannot be deduced with certainty and ease from a simple grammatical rule. They thus ought to give full information about the prepositions by which verbs are connected with the words they govern ..."

Wat werkwoorde betref, is Sweet se vereiste intussen waarskynlik deur woordeboeke soos Oxford Advanced Learner's Dictionary of Current English (voortaan OALDCE) met sy 25 basiese werkwoordpatrone en Longman Dictionary of Contemporary English (voortaan LDOCE) met sy patrone gebaseer op die Grammar of Contemporary English (Quirk et al. 1972) nagekom. Alhoewel albei woordeboeke inligting oor die komplementeringsmoontlikhede van adjektiewe bevat, verskaf hulle nie genoeg detail om die aanleerder in staat te stel om uit te vind "whether valency theory is 'useful for' or 'not available to him', (...) whether it may be 'important for him to find' and/or 'important that he should find" such information in a dictionary" (Herbst 1984: 1). Dit is nie duidelik op grond waarvan die samestellers besluit het om die komplementeringsmoontlikhede van ' $n$ adjektief wel te spesifiseer of dit nie te spesifiseer nie. Herbst (1984: 1) is van mening dat die toepassing van die valensieteorie op Engelse adjektiewe kriteria kan voorsien op grond waarvan 'n besluit met betrekking tot moontlike komplementering geneem kan word.

Vanuit 'n linguistiese oogpunt kan die konsep valensie volgens Herbst (1984: 1) omvattender beskou word as wat die geval is met die meer tradisionele konsepte van oorganklikheid en reksie ("government"). 'n Werkwoord wat byvoorbeeld tradisioneel as 'n oorganklike werkwoord beskryf 'word, kan ook beskou word as ' $n$ werkwoord wat ' $n$ valensie van twee het en 'n direkte voorwerp regeer. Die werkwoord vang het byvoorbeeld twee sintaktiese gleuwe wat gevul moet word. Vergelyk die volgende voorbeeld:

(8) Jannie vang die bal.

Die valensieteorie word onder andere deur Lyons 1977, Leech $1981^{2}$ en Matthews 1981 bespreek. 
Valensie omvat meer as net die getal uitdrukkings waarmee 'n werkwoord mag of moet verbind. Valensie beteken dat daar ook rekenskap gegee moet word van die verskille in lidmaatskap van die stelle uitdrukkings wat met verskillende werkwoorde kan kombineer. Die werkwoorde give en put (in hul algemeenste gebruike) het albei 'n valensie van drie, maar hulle verskil ten opsigte van die drie uitdrukkings wat hulle regeer: give regeer 'n onderwerp, 'n direkte voorwerp en 'n indirekte voorwerp, terwyl put 'n onderwerp, 'n direkte voorwerp en 'n rigtinggewende lokatief regeer. 'n Mens kan dus sê dat hulle ten opsigte van valensie verskil: hulle word geassosieer met twee verskillende valensiestelle (Lyons 1977: 486-487).

Leech (19812: 198) definieer valensie as "the potential that a word possesses for combining with other words both syntactically and semantically." Die valensie van ' $n$ werkwoord is die getal en tipe sintaktiese gleuwe wat gevul moet word om die betekenis van die werkwoord te voltooi. Vergelyk:
(9) 1 valensie
2 valensies
3 valensies
a speak
$a$ say $b$
a remind $b$ of $c$

Die volgende belangrike punte met betrekking tot valensie moet in gedagte gehou word:

- Werkwoorde kan net soos ander tipes woordsoorte dubbelsinnig wees. Hierdie dubbelsinnigheid kan toegeskryf word aan die feit dat dieselfde werkwoord verskillende getalle valensies kan hê. In een betekenisonderskeiding kan sowel say as speak byvoorbeeld bivalent wees: The actor spoke his lines en The actor said his lines.

-. Valensies kan elemente bevat wat opsioneel gerealiseer word, byvoorbeeld die opsionele direkte voorwerp in Jill was writing/Jill was writing a letter.

- Adjektiewe het ook valensies. 'n Adjektief soos happy is monovalent (a be happy) maar ' $n$ adjektief soos glad is bivalent ( $a$ is glad at/about $b$ ). Laasgenoemde voorbeeld illustreer dat bivalensie nie net funksioneel (onderwerp $\times$ voorwerp) of kategoriaal (infinitiefsin $\times$ NS) gemotiveer word nie, maar ook leksikaal, dit wil sê ten opsigte van twee woorde wat dieselfde funksie en woordsoort het. Glad verbind met 'n setsel, maar verskillende leksikale elemente wat tot dié kategorie behoort (at en about) kan met glad verbind.

Die leksikografies belangrike vraag oor hoe konstruksies wat individuele woorde karakteriseer, geskei kan word van daardie konstruksies wat nie individuele woorde karakteriseer nie, word in die valensieteorie gereflekteer deur die onderskeid tussen komplemente (Fr.'actants, D. Ergänzungen) en perifere elemente (circonstants, Angaben). Die komplemente, wat in verpligte en opsionele komplemente verdeel kan word, vul die valensieposisies van die regeren- 
de element, terwyl die voorkoms van perifere elemente geensins bepaal word deur of tipies is van ' $n$ regerende element nie. Perifere elemente maak nie deel uit van valensie nie en dit is slegs die komplemente wat in die woordeboek in die regerende lemma se artikel opgeneem behoort te word. Volgens Herbst (1984: 1) kan daar dus gesê word, dat indien die valensieteorie 'n bydrae tot leksikografie wil lewer, dit in staat moet wees om betroubare kriteria te verskaf vir die onderskeid tussen komplemente en perifere elemente.

Die vraag is hoe verpligte en perifere komplemente van mekaar geskei kan word. Die eerste of verpligte tipe komplement kan deur middel van ' $n$ eenvoudige weglatingstoets gedefinieer word (Herbst 1984: 1).

Vergelyk die onderstaande voorbeeld waarin aan mense geklassifiseer kan word as 'n verpligte komplement van gewoond:

(10) (a) Hy is gewoond aan mense omdat

(b) Hy is gewoond

ongrammatikaal is.

By hierdie kriterium speel nie slegs sintaktiese faktore 'n rol nie, maar ook semantiese faktore.

Gevolglik is $n a+$ NS in ' $n$ sin soos

(a) Jan is gek na lekkers

'n verpligte komplement, want die betekenis van gek in 11(a) verskil (op grond van die setsel $n a$ ) aansienlik van gek in 11(b).

(b) Jan is gek

Wat verpligte komplemente betref, mag hulle nie weggelaat word nie, terwyl die teendeel vir opsionele komplemente geld. Ter illustrasie:

(c) Jan is gek omdat hy die snaaksste dinge doen

Weglaatbaarheid kan dus as kriterium dien om verpligte elemente te isoleer. Hierdie kriterium kan nietemin nie sonder meer gebruik word om tussen opsionele en perifere elemente te onderskei nie, soos blyk uit

(d) Jan is gek in die namiddag

aangesien perifere elemente weglaatbaar is. As gevolg van die feit dat perifere elemente onafhanklik van die valensie van ander woorde in 'n sin voorkom, kan daar geargumenteer word dat hulle nie net weglaatbaar is nie, maar ook vryelik bygevoeg kan word. Dit geld nie vir opsionele komplemente wat nie 
so vryelik aan ander sinne gevoeg kan word nie aangesien hulle optrede afhanklik is van die valensie van die regerende woord.

In die voorafgaande bespreking is daarop gewys dat perifere elemente onafhanklik van enige vereistes, weggelaat of bygevoeg kan word. Matthews (1981: 127) wys nogtans daarop dat die byvoeging van perifere elemente "free of any restriction but the need to make sense" is.

Semantiese oorwegings speel dus wel 'n rol by die byvoeging van perifere elemente. Hoewel rondom sy lessenaar as perifere element aan 10(a) gevoeg kan word soos in die volgende sin:

(c) Hy is gewoond aan mense rondom sy lessenaar

is dit leksikografies irrelevant vir gewoond.

Gegee die woordeboek se primêre gerigtheid op die leksikale semantiek, sal valensie-inligting nie verder as die eerste kombinasievlak hoef te strek nie. Gewoond, as lemma, se kombinasie met aan + NS moet dus gegee word. Vrye toevoeging is nie ter sake nie.

Hoewel die riglyn van vrye toevoeging mag help om in sommige gevalle komplemente van perifere elemente te skei, is dit nie op sigself voldoende om die onderskeid te bepaal nie.

Dit blyk ook waar te wees van die ander kriteria wat in hierdie verband bespreek is, veral met betrekking tot verbale valensie. Emons (1978: 18-21), wat die valensiebenadering op Engelse werkwoorde toegepas het, beweer dat mens grootliks op verligte intuisie moet staatmaak ten einde tussen opsionele en perifere elemente te onderskei. Matthews (1981: 136) wat vyf kriteria gebruik om tussen komplemente en perifere elemente te onderskei, kom eweneens tot die gevolgtrekking "that we are left with a mass of boundary cases, subtle ambiguities, and gradience generally".

Alhoewel die onderskeid tussen verpligte komplemente, opsionele komplemente en perifere elemente nie altyd duidelik is nie, mag so 'n differensiëring nie uit linguistiese beskrywing weggelaat word nie. Aangesien hierdie onderskeid as arbitrêr beskou kan word, is dit belangrik om dit op duidelik gedefinieerde kriteria te baseer. So 'n onderskeid kan dan vrugbaar in die leksikografie toegepas word.

Herbst (1984: 6) beklemtoon die belangrikheid van die onderskeid tussen verpligte en opsionele komplemente en tussen komplemente en perifere elemente: "... it is of great importance for the foreign learner to be able to distinguish whether the constructions given for a word in the dictionary are merely possible uses of that word or whether the word must be used with a certain construction (at least in a certain meaning)."

In 'n aanleerderwoordeboek is die volgende inligting byvoorbeeld noodșaaklik: 
(12)
(a) Hy is ryk.
(b) Hy word ryk uit goud.
(c) Siberië is ryk aan olie en minerale.
(d) Hy is ryk aan ervaring.

Daar moet aangetoon word dat uit goud in (b) perifere elemente is, terwyl aan + aanvulling in (c) en (d) verpligtend is in die besondere betekenis.

Hy is ryk

beteken dat hy baie geld en goed besit, terwyl

Hy is ryk aan $X$

beteken dat hy ruim voorsien is van $X$.

Sodra aan by ryk gevoeg word, verander die betekenis dus. Vergelyk ook:

(13) Sy is erg vatbaar vir verkoue.

(14) Hy is vatbaar vir goeie indrukke.

In albei sinne is vir + aanvulling verpligtend. Vergelyk:

(15) Sy is erg vatbaar.

(16) Hy is vatbaar.

In Afrikaanse woordeboeke word hierdie onderskeid glad nie aangedui nie.

\subsection{Linguistiese kategorieë wat as adjektiefkomplemente kan optree}

Die volgende aspek met betrekking tot adjektiefkomplemente wat bespreek word, is die verskillende linguistiese kategorieë wat as adjektiefkomplemente kan optree. Die volgende elemente kan as adjektiefkomplemente in Engels voorkom:

a prepositional phrases (Alcoholic drinks are not available to people under eighteen)

b infinitive clauses (He is willing to be honest)

c ing-clauses (It is handy living on campus)

d that-, if-en wh-clauses (It is nice that/would be nice if you could come; Judith was not certain whether/where/when she had met Dennis) (Herbst 1984: 5). 
In Afrikaans sou a, b en $\mathrm{d}$ moontlik kon geld op basis van die vraagkriterium soos voorgestel deur Herbst (1984: 5). Daarvolgens neem opsionele komplemente vraagvorme wat wie of wat bevat, terwyl perifere elemente nie hierdie vrae toelaat nie.

Vergelyk die volgende voorbeelde:

(a) dit was goed, om eerlik te wees,

(b) Dit was goed om eerlik te wees.

Slegs in (b) kan die vraag: Wat was goed? gestel word. Voorbeèld (b) bevat dus die opsionele komplement om eerlik te wees, terwyl dieselfde element in (a) 'n perifere element is.

Daar sal egter deeglike navorsing gedoen moet word om vas te stel watter kriteria vir Afrikaans geld. Binne die raamwerk van die valensieteorie kan 'n onderskeid dan getref word tussen komplemente en perifere elemente by adjektiewe en op grond daarvan kan die konstruksies wat in 'n aanleerderwoordeboek opgeneem moet word, en die vorm waarin dit opgeneem moet word, bepaal word.

Herbst (1984: 6) sê dat daar geargumenteer kan word dat woordeboeke vir die aanleerder nie noodwendig daarop gerig moet wees om 'n omvattende beskrywing van die komplementeringsmoontlikhede te gee nie, aangesien sommige patrone nie algemeen voorkom nie of beperk is tot sekere stylvlakke. Indien dit nie die geval is nie, kan hulle insluiting meer misleidend as bruikbaar vir die aanleerder wees. Aan die ander kant moet daar onthou word dat woordeboeke soos OALDCE en LDOCE nie slegs bruikbare instrumente vir die aanleerder vir enkodering is nie, maar dat hulle ook van groot belang is vir die onderwyser van die vreemde taal wat die woordeboek sal raadpleeg om vas te stel of 'n konstruksie (soos gebruik deur 'n aanleerder) aanvaarbaar is al dan nie. Herbst (1984: 6) kom dan tot die gevolgtrekking dat woordeboeke soos OALDCE en LDOCE wel na omvattendheid moet streef. Dit is tog wenslik dat patrone wat nie algemeen voorkom nie, ooreenkomstig die beperking gemerk moet word, byvoorbeeld deur etikette soos seldsaam, informeel, ensovoorts.

'n Gebrek aan ruimte kan as 'n verdere argument aangevoer word vir die nie-opname van patrooninligting. Herbst (1984: 6) wys nietemin daarop dat patrooninligting nie baie ruimte in beslag hoef te neem nie. Verder kan inligting oor komplemente aansienlik verbeter word indien die onderskeid tussen komplemente en perifere elemente by die saamstel van voorbeeldsinne in ag geneem word.

In die geval van die adjektief available, gee LDOCE byvoorbeeld slegs voorbeelde wat perifere elemente bevat: There is water available at the hut; I' $m$ sorry, sir, these shoes are not available in your size. Indien hierdie sinne vervang sou word deur sinne met komplemente soos Alcohol is not available to children en There is no space available for parking your car there sal die betekenis van die 
adjektief ewe goed geillustreer word. Terselfdertyd word relevante sintaktiese inligting gegee sonder dat meer ruimte benodig word (Herbst 1984: 6).

\section{Slotwoord}

Om reg te laat geskied aan sy funksie as aanleerhulpmiddel, behoort ' $n$ aanleerderwoordeboek baie meer grammatiese inligting as standaardwoordeboeke te bevat. Inligting moet ook meestal eksplisiet aangedui word om verwarring by aanleerders te voorkom. Ten opsigte van adjektiewe moet die volgende grammatiese inligting in aanleerderwoordeboeke aandag geniet: 'n aanduiding of adjektiewe verbuig moet word of nie, trappe van vergelyking, 'n volledige identifikasie van adjektiewe, ' $n$ aanduiding of adjektiewe net attributief of net predikatief kan optree, die verskillende wyses waarop so en sulke gebruik word, die feit dat nie alle "voltooide deelwoorde" uit lydende vorme met wees gevorm kan word nie, die voorsiening van 'n spellys met die name van mense, lande, plekke, volkere, stamme, tale, asook afleidings daarvan, kruisverwysings tussen selfstandige naamwoorde/werkwoorde en hul adjektiwiese korrelate indien daar groot verskille tusen hulle is, en die aandui van adjektiefkomplemente. Meer gedetailleerde grammatiese inligting, soos hierbo uiteengesit, kan daartoe lei dat aanleerderwoordeboeke effektiewe aanleerhulpmiddels word, wat aanleerders kan help om selfstandig nuwe, natuurlike sinne in Afrikaans te skep.

\section{Verwysings}

\section{Woordeboeke}

Bosman, D.B., I.W. van der Merwe en L.W. Hiemstra. 19848. Tweetalige Woordeboek/Bilingual Dictionary. Kaapstad: Tafelberg.

De Villiers, M. e.a. 19856. Nasionale Woordeboek. Kaapstad: Nasou.

Hornby, A.S. e.a. 1974. Oxford Adzanced Leamer's Dictionary of Current English. Oxford: Oxford University Press.

Odendal, F.F. e.a. 19792. Verklarende Handwoordeboek van die Afrikaanse Taal. Doomfontein: Perskor.

Proctor, P. e.a. 1978. Longman Dictionary of Contemporary English (LDOCE). Londen, Harlow: Longman.

\section{Ander bronne}

Carstens, W.A.M. 1991. Nomie vir Afrikaans: Enkele riglyne by die gebruik van Afrikans. P'retoria: Academica. 
De Vill iers, M. 1983. Afrikaanse grammatika vir volwassenes. Coodwood: Nasou.

Emons, R. 1978. Valenzgrammatik für dos Englische. Tübingen: Niemeyer.

Gouws, R.H. 1986. Die taalkundige grondslae van die teoretiese leksikografie en die praktiese neerslag van taalkundige inliging in woordeboeke. RCN-verslag.

Herbst, T. 1984. Adjective Complementation: A Valency Approach to Making EFL Dictionaries. Applied Linguistics 5(1): 1-11.

Ilson, R. (Red.). 19855. Dictionaries, Lexicography and Language Leaming. Oxford: Pergamon Press.

Jackson, H. 1985. Grammar in the Dictionary. Uson, R. (Red.). 19855: 53-59.

Leech, G.N. 19812. Semantics. Harmondsworth: Penguin.

Lyons, J. 1977. Semantics. Volume 1 \& 2 . Cambridge: Cambridge University Press.

Matthews, P. 1981. Syntax. Cambridge: Cambridge University Press.

Ponelis, F.A. 1979. Afrikanse sintaksis. Pretoria: Van Schaik.

Quirk, R. e.a. 1972. A Grammer of Contemporary English. Londen: Longman.

Sweet, H. (1899/1964). The Practical Study of Languages. Londen: Dent (heruitgawe Londen: Oxford University Press). 